\title{
Patateste Farklı Ortam ve Dönemlerde Yapılan Melezleme ve Melez Tohum Elde Edilmesini Etkileyen Faktörler
}

\author{
${ }^{*}$ Güngör YILMAZ ${ }^{1}$ Nejdet KANDEMIR ${ }^{1}$ Yusuf YANAR ${ }^{2}$ Yasin B. KARAN ${ }^{1}$ \\ Ahmet KINAY ${ }^{1} \quad$ Şaziye DÖKÜLEN ${ }^{1}$ \\ ${ }^{1}$ Gaziosmanpaşa Üniversitesi, Ziraat Fakültesi, Tarla Bikileri Bölümü, Tokat \\ ${ }^{2}$ Gaziosmanpaşa Üniversitesi, Ziraat Fakültesi, Bitki Koruma Bölümü, Tokat \\ *Sorumlu yazar e-posta (Corresponding author e-mail): gungor.yilmaz@gop.edu.tr
}

Öz

Bu araştırmada, üstün özelliklere sahip ileri patates klonları ile bazı yerel patates çeşitleri ve ticari çeşitler arasında melezlemeler yapılarak, melez tohumların elde edilmesi amaçlanmıştır. Çalışma, Tokat şartlarında 2014 yılı ilkbahar döneminde başlayıp, 2015 yılı kış döneminde de devam ettirilerek, 2014 ve 2015 yıllarında yürütülmüştür. Patateste melezleme işlemleri 2014 yılında cam ve tül sera ile düşük (650 m) ve yüksek rakımlı (1200 m) açık alanlarda yapıımıştır. Araştırmanın 2014-2015 kış dönemi polikarbon sera ortamında yürütülmüştür. Elde edilen sonuçlara göre 2014 yılı yaz dönemi açık alan ve tül sera şartlarında 15 kombinasyonun 14'ünde 1260 çiçek melezlenmiş, bunlardan 65'i meyve oluşturabilmiş ve 1831 adet melez tohum elde edilmiştir. 2014 yılı yaz döneminde zaman zaman aşırı yağış ve özellikle yüksek sıcaklıklardan dolayı melezleme başarısı olumsuz etkilenmiş, bu yüzden melezleme çalışmalarına kış döneminde polikarbon serada devam edilmiştir. Bu dönemde yapılan melezleme çalışmalarında 15 kombinasyonda yaklaşık 1602 çiçekte melezleme yapılmış ve halen 203 meyveden 13302 adet melez tohum elde edilmiştir. Yaz döneminde melezlenen çiçeklerin \%5.2' si meyve bağlamış iken, kış döneminde bu oran \%12.7 olmuştur. Benzer şekilde yaz döneminde meyve başına 28.2 adet tohum elde edilmiş iken, kış dönemi melezlemelerinde bu sayı 65.5'e yükselmiştir. Diğer taraftan, yaz döneminde yüksek rakımlı açık alan ve tül sera şartlarında yapılan melezlemelerden daha iyi sonuçların alındığı da belirlenmiştir.

Anahtar Kelimeler: Patates, Solanum tuberosum, emaskulasyon, melezleme, melez patates tohumu

\section{Crossing of Potato in Different Growing Conditions and Factors Affecting Hybrid Seed Production}

\begin{abstract}
Aim of the present study was to make crosses between some advanced potato clones, some local potato varieties and commercial varieties with superior properties and to produce hybrid seeds. The study started in 2014 spring and continued through the winter of 2015. In 2014, crosses were made in glass and cloth greenhouses and under field conditions in low $(650 \mathrm{~m})$ and high (1200 m) altitude locations. Crosses in 2014-2015 winter period were made in a polycarbonate greenhouse. In 2014 summer period under field and cloth greenhouse conditions, 1260 flowers were used for crossing in 14 of the 15 cross combinations. A total of 65 fruits were obtained and they contained 1831 hybrid seeds. During 2014 summer period, excess rainfall and especially high temperatures negatively affected the success of crossing. Therefore, crosses were continued under polycarbonate greenhouse conditions during the winter period. During this period, 1602 crosses were made in 15 combinations and a total of 13302 seeds were obtained in 203 fruits. Percentage of fruit set was $5.2 \%$ in crosses made in summer period and $12.7 \%$ in crosses made in winter period. Similarly, number of seeds per fruit set was 28.2 in summer period and 65.5 in winter period. It was found that crossing in summer time was more successful under high altitude field and cloth greenhouse conditions.
\end{abstract}

Keywords: Potato, Solanum tuberosum, emasculation, crossing, hybrid potato seed 


\section{Giriş}

$D$ atates, insan beslenmesinde ve sanayide kullanılan önemli bitkilerden biridir. Dünyada 376 milyon ton (Anonim, 2013), Türkiye'de ise 4.2 milyon ton üretimi yapılmaktadır (Anonim, 2014). Yumruları kullanılan patatesin farklı kullanım amaçlarına uygun çok sayıda çeşidi bulunmaktadır. Türkiye'de 100'e yakın patates çeşidinin yetiştiriciliği yapılmakla birlikte bunlardan, 2015 yılında tescil edilen sadece üç tanesi yurt içinde Islah edilen çeşitlerdendir (Anonim 2015). Bu yüzden Türkiye'nin çok sayıda farklı özelliklere sahip yerli patates çeşitlerine intiyacı vardır. Patateste yeni bir çeşit geliştirmek için uygulanan konvansiyonel ıslah programları, uygun ebeveynler arasındaki melezlemelerle başlayıp, klonal çoğaltım ve seleksiyonla devam etmektedir (Brown 2011).

Melezlemede ilk aşama, kullanılacak ebeveynlerin seçimidir. Burada ıslahçının amacı ve hedefi önemlidir. Eğer ıslahçının nihai hedefi ticari bir çeşit elde etmekse, o zaman arzu edilen karakterleri taşıyan hatlar-klonlar üzerinde yoğunlaşması gerekmektedir. Örneğin, ıslahçı bir çeşitteki yüksek verimle diğer bir çeşidin yumru şeklini kombine etmek isteyebilir. Bu durumda çok sayıda karakterin göz önüne alınması gerekmektedir. Diğer taraftan verimle birlikte hastalıklara da dayanıklılık hedeflenebilir. Bundan sonra melezlerde beklentilere göre seçim yapmak gerekmektedir (Harris 1992). Patateste melezleme ile yeni çeşit geliştirme aşamaları şu şekildedir; amaca uygun ebeveynlerin seçimi, bunlar arasında melezlemelerin yapılması, elde edilen tohumlardan fideler üreterek $F_{1}$ generasyonu ile seleksiyon çalışmalarına başlanılması, seleksiyon çalışmaları sonucu istenen karakterleri taşıyan klonların seçimi ve seçilen klonlar yeterli miktara ulaştığında bir kaç lokasyonda test edilerek istenen karakterler yönüyle standartları geçen yeni çeşitlerin tescil ettirilerek, üretimlerinin yapılmasıdır (Poehlman and Sleper 1995). Struik and Wiersema (1999)'a göre, tüm özellikler bakımından mükemmel bir patates çeşidi geliştirmek mümkün değildir. Genel olarak bir çeşidin en önemli karakteristikleri; yüksek verim, kalite, önemli yerel hastalıklara karşı dayanıklılık ve pazar isteklerine uyumlu özellikler taşıması şeklinde sayılabilir. Heterozigot klonal ebeveynlerin melezlenmesiyle oluşan patates $\mathrm{F}_{1}$ 'lerinden yapılacak olan seleksiyon, seçime konu olan materyalin genetik yapısı sabitlendiğinden dolayı kolay ve hızlıdır. Ancak, patateste melezleme öncesi çiçeklenme ve melezleme sonrası meyve bağlama sorunlarıyla sıklıkla karşılaşılmaktadır. Patateste çiçeklenme için uzun ve serin sayılabilecek günlere ihtiyaç bulunmaktadır (Simmonds and Smartt 1999). Dominant genlerin etkisiyle, fenotipleri aynı olsa bile birçok patates genotipi birbirinden farklı olacağından, özellikle patates gibi tetraploid türlerde, istenen karakterlere sahip bir çeşide kavuşabilmek için mümkün olduğu kadar çok sayıda melezleme yaparak $F_{1}$ bitkileri yetiştirilmeli ve bunlardan çok sayıda yeni klonlar üretilmelidir. (Brown and Caligari 1989). Benzer şekilde Mendoza (1987) da mümkün olduğu kadar fazla sayıda melezleme yapılmasını ve her melezlemenin ürünü olan meyvelerden alınacak tohumların her birinden yetiştirilecek patates bitkilerinin yumrularını (klonları) ayrı ayrı sıralara dikmekle işe başlandığını bildirilmiştir. Melezleme işlemlerinde daha başarılı olabilmek için bitki üzerinde daha çok çiçek oluşumu ve çiçeklenme süresinin uzun olması istenir. Patates bitkisinde, çiçek oluşumunun sağlanması; yumruları biriket üzerine dikilmesi, patates sürgünlerinin domates fidesi üzerine aşılanması, bitkiye gibberellik asit (GA3) uygulanması, bitkilerin uzun gün koşullarında yetiştirilmesi gibi uygulamalarla sağlanabilmektedir (Esendal 1990; Er ve Uranbey 2009). Gün uzunluğunun 16 saat olması çiçeklenmeyi teşvik etmekte ve melezleme başarısını arttırmaktadır. Almekinders and Struik (1996) de patateste çiçeklenme ve meyve bağlamada gün uzunluğu ve sıcaklığın etkili olduğunu, en iyi çiçeklenmenin uzun gün şartlarında yaklaşık 16 saat, nemin yüksek ve sıcaklığın düşük olduğu şartlarda meydana geldiğini belirtmişlerdir. Yine aynı araştırıcı gün uzunluğunun 12-14 saat, gece sıcaklığının ise $15-20^{\circ} \mathrm{C}$ arasında olmasının patateste çiçek oluşumu ve meyve bağlama için uygun olduğunu, kısa gün şartlarında çiçek tomurcuklarının döküldüğünü veya bazı çeşitlerin yeterince çiçeklenemediğini belirtmişlerdir. Diğer taraftan melezleme işlemi için en iyi tozlama zamanı sabahları çiçekler tamamen açıldıktan kısa bir süre sonradır. Tozlanmadan sonra 6-8 hafta içerisinde tohum gelişerek, meyveler olgunlaşır (Fehr and Hadley 1980). Melezlemede başarı oranı; başta genotip faktörü olmak üzere, ıslahçının becerisi melezleme dönemindeki başta gün uzunluğu olmak üzere, sıcaklık, gece gündüz sıcaklık 
farkı ve tozlanmanın yapıldığı dönemde bitkilerin gelişme durumları gibi pek çok faktör tarafından etkilenmektedir (Kurt 2004; Muthoni et al. 2012). Patateste melezleme başarısını artırmanın bir başka yolu da bitkinin yumru oluşturma yeteneğinin engellenmesi veya stolonların kesilmesi de çiçeklenmeyi ve meyve bağlamayı olumlu yönde etkilediği Fehr and Hadley (1980) tarafından bildirilmiştir.

Markarov (2002), gibberellin aktivitesinin patateste çiçeklenmeyi teşvik ettiğini, kısa gün ve $15-20^{\circ} \mathrm{C}^{\prime}$ lik sıcaklık şartlarında $\mathrm{ABA}$ seviyesinin yükselmesiyle çiçeklenmenin olmadığını aksine yumru oluştuğunu, ancak kısa gün koşullarında geceleri düşük sıcaklık şartları $\left(5-6^{\circ} \mathrm{C}\right)$ durumunda, gibberellik asidin yıkımının azaldığı ve bitkilerin uzun gün bitkisi gibi davranarak çiçeklenmeyi teşvik ettiğini, bunun yanında yumru da oluşturabildiğini bildirmektedir. Benzer şekilde Metzger (1990), düşük sıcaklık şartlarında kaurenik asidin Gibberellik aside dönüştüğünü, bu yüzden uzun gün şartlarında absisik asit aktivitesinin düşük, kısa gün+ılıman gece ve kısa gün+düşük sıcaklık (gece) şartlarında ise yükselebildiğini belirtmiştir. Markarov (2002)'un çalışmasında gibberellik asidin çiçeklenmeyi, absisik asidin ise yumru oluşumuna uyarıcı etki yaptığı, bu yüzden yüksek gibberellik asit içerikli uzun günlerde sadece meyve, kısa gün ılıman gecelerde ise absisik asit içeriğinin artmasından dolayı yumruların oluştuğu görülmüştür. Patateste melezleme sonrası meyve bağlama ve bu meyvelerin gelişiminin sağlanması da önemlidir. Bu konuda Gopal (1994) yapraklara giberellik asit püskürtülmesinin meyve bağlamayı arttırdığını bildiriken, Sleper and Poehlman (2006) sera şartlarında patatesin, Solanacea familyasından başka bir bitkinin üzerine aşılanması ve sıcaklığın $22^{\circ} \mathrm{C}$ 'nin altında olacak şekilde ayarlanması ile yeni yumru oluşumunun engellenmesi için stolonların ucunun kesilmesi önerilerini de yapmışlardır.

\section{Materyal ve Yöntem}

Bu araştırma 2014 ve 2015 yıllarında TokatKazova ve Tokat-Artova şartlarında yürütülmüştür. Araştırmada, aşağıdaki kombinasyonlara ait melezlemeler; TokatKazova (640 m) açık alan, tül sera, cam sera ve polikarbon sera ile Tokat-Artova'da (1200 m) açık alan ve tül sera şartlarında yürütülmüştür. Tokat-Kazova polikarbon serada yapılan melezlemeler 2014-2015 kış döneminde, diğerleri ise 2014 yılı yaz vejetasyonunda yapılmışır. Araştırmada aşağıdaki kombinasyonlarda melezlemeler yapılarak, melez tohumlar elde edilmiştir.

Dikim işlemleri, ebeveynlerin çiçeklenme zamanlarını denk getirebilmek ve daha fazla melezleme yapabilmek için her bir alan için farklı tarihlerde yapılmıştı. Buna göre; Tokat'ta cam seraya yumruların dikim tarihleri: 6,18 ve 26 Mart, tül seraya fide dikimleri: 19 ve 28 Nisan, açık alana 1,14 ve 27 Nisan, TokatArtova'da açık alana 10, 19 ve 28 Mayıs, TokatArtova tül seraya fide dikimi ise 24 Mayıs tarihlerinde yapılmıştır. Sera ortamlarına dikim işlemleri $33 \times 26 \mathrm{~cm}$ olan $1 / 3$ oranında torf+toprak ve kum karışımlı saksılara, açık alanlara dikim ise $100 \times 70 \mathrm{~cm}$ aralıklarla her bir ebeveynden her dikim döneminde 5'er bitki olacak şekilde yapılmıştır. Kış dönemi polikarbon sera ortamındaki çalışmalar için dikim işlemleri 10 Kasım 2014'den itibaren üçer hafta arayla olmak üzere Aralık sonuna kadar devam etmiştir. Çıkıştan itibaren her ortamdaki bitkiler izlenerek, gerekli çapalama, sulama, gübreleme, boğaz doldurma, yan dallarda budama, stolonlarda kesme ve ilaçlama gibi agronomik işlemleri yapılmıştır. Melez kombinasyonlara ait ebeveynler, çiçek

Çizelge 1. Melezlemede kullanılan ebeveynler ve melez kombinasyonları

Table 1. Parents and combinations used in crosses

\begin{tabular}{llll}
\hline Kombinasyon No & Ebeveynler & Kombinasyon No & Ebeveynler \\
\hline 1 & A2/11 X T6/28 & 9 & A3/223 X Megusta \\
2 & A3/110 X A2/11 & 10 & Başçiftlik Beyazı X A13/1 \\
3 & A10/15 X A3/223 & 11 & Başçiftlik Beyazı X Megusta \\
4 & A7/12 X A10/15 & 12 & Başçftlik Beyazı X Van Gogh \\
5 & A8/34 X A13/1 & 13 & Aleddiyan Sarısı X Megusta \\
6 & T4/4 X T6/28 & 14 & Aleddiyan Sarısı X A2/11 \\
7 & A2/11 X Melody & & \\
8 & A7/12 X Van Gogh & 15 & Aleddiyan Sarısı X T6/28 \\
\hline
\end{tabular}


tomurcuğu oluşumundan itibaren melezleme için yakın takibe alınmışlardır. Emaskulasyon işlemi ana bitkilerin çiçekleri açılmadan (belli bir iriliğe ulaşmış, ancak taç yaprakları henüz açılmamış) ince uçlu pens yardımıyla taç yapraklar nazik bir şekilde açılarak, stigmaya zarar vermeden 5 adet erkek organın anter keseleri de parçalanmadan, çiçekten uzaklaştırılması şeklinde günün erken saatlerde yapılmıştır. Melezleme amacıyla seçilen ana bitkilerin çiçekleri henüz açılmadan önce (belli bir iriliğe ulaşmış, ancak taç yaprakları henüz açılmamış) pens yardımıyla açılarak emaskulasyon (anter keselerinin uzaklaştırıması) işlemi yapılır. Bu işlem günün erken saatlerinde yapılır. Çiçek topluluğu içinde emaskule edilenlerin dışındaki çiçekler uzaklaştııılarak, emaskulasyonun kolaylaştırılması ve muhtemel bulaşıklıkların önlenmesi sağlanır (Poehlman and Sleper 1995). Emaskulasyon işlemi sonrasında dişi organın zarar görmemesi için herhangi bir izolasyon işlemine gerek olmadığı da bildirilmiştir (Fehr and Hadley 1980). Melezleme işlemi, emaskule edilen ana bitkiye ait çiçeklerin, polen verme olgunluğuna gelen hazır baba bitki çiçekleri varsa, anter keselerinden alınan polenlerin, dişi bitkinin stigmasına bulaştırılması şeklinde yapılmıştır. Emaskulasyondan sonra, tozlayıcı çiçek hazır değilse bir sonraki gün melezleme yapılmıştır. Kış döneminde çiçek tomurcukları oluşumu Ocak-2015'in ilk günlerinden itibaren başlamış, emaskulasyon ve melezleme faaliyetleri işlemleri 16.01.2015'ten başlayıp, Mayıs-2015 sonuna kadar devam etmiştir. Kış dönemi sera ortamında bitki gelişimi, çiçeklenme ve melezleme başarısını arttırmak için uzun gün koşulları (16 saat ışıklanma süresi) suni ışıklandırmayla sağlanmış, sera içi sıcaklık, kontrollü mekanizmalar devreye sokularak gece/gündüz $16 / 22^{\circ} \mathrm{C}^{\prime}$ ye ayarlanmıştır. Melezlenen çiçeklerde döllenme olmuş ise, yaklaşık bir hafta (5-8 gün) sonra meyve ovaryumda bir şişme, bundan 3-5 gün sonra da mini kapsüller kendini göstermekte ve üst kısmındaki taç yaprak kalıntısı da düşmektedir. Meyveler görüldükten sonra dökülüp kaybolmamaları için hazırlanan tül keselerle koruma altına alınmışlardır. Melez meyveler gelişmelerini sürdürdükçe irileşmekte, fizyolojik olgunluğunu tamamlayan meyvelerin içindeki tohumlar, her bir melez kombinasyon için ayrı ayrı olması üzere, su içerisinde ayıklanıp, alınmışlar ve kurutularak küçük kavanozlarda muhafazaya alınmışlardır.

\section{Bulgular ve Tartışma}

Patateste farklı mevsimlerde yapılan melezlemeler sonrası elde edilen bulgular Çizelge 2'de verilmiştir. Buna göre kış dönemi sera şartlarında yapılan melezlemelerin, yaz döneminde yapılan melezlemelerden meyve bağlama ve melez tohum elde etme bakımından daha iyi olduğu açıkça ortaya çıkmıştır. Kış döneminde patates bitkilerinin generatif gelişmelerine uygun çevre şartalarının sera ortamında kontrollü bir şekilde oluşturulmasından dolayı, bitkilerde daha fazla çiçek oluştuğu, bu yüzden denemede yer alan 15 kombinasyonda yaz döneminde 1260 çiçekte melezleme işlemi yapılmış iken, kış döneminde bu sayının 1602'ye çıktığı, melezlenen bu çiçeklerde yaz döneminde 65 meyve elde edilmiş iken, kış dönemindekilerden 203 adet meyve elde edildiği görülmüştür (Çizelge 2). Patateste melezleme başarııında en önemli faktörlerden birisi bitkilerde çiçeklenmenin yeterince sağlanmasıdır. Bunun için uzun gün şartları ve gece gündüz sıcaklık farklıı̆̆ının belirginliği önemlidir (Muthoni et al. 2012). Burada gecelerin daha serin olması istenmektedir. Patateste çiçeklenme ve melezleme başarısı için bitkilerde gibberellik asit sentezinin belirleyici olduğu, uzun gün ve serin şartların $\mathrm{GA}_{3}$ sentezini arttırdığı Chailakhyan (1971) tarafından bildirilmiştir. Gövde gelişimi ve çiçeklenmenin teşviki için çeşitli yöntemler uygulanmakta olup, bunlardan birisi bitkilerin bir tuğla üzerinde yetiştirilerek stolonlarının ucunun kesilmesidir (Gopal 1994). Bazı araştırıcılar bunun için bitkilerin önce saksı ortamında fide haline getirildikten sonra hazırlanan ortamlara dikilmesini ve burada stolonların kesilmesini önermişlerdir (Fehr and Hadley 1980). Melezleme sonrası oluşması istenen ürün meyve ve tohum sayısıdır. Bu yönden de yaz döneminde melezleme yapılan çiçeklerin \%5.2'sinde meyve oluşmuş iken, kış dönemindeki melezlemelerde bu oran \%12.7'ye yükselmiştir. Benzer şekilde alınan melez tohumsayılarında da yaz dönemindeki 1831 adet tohuma karşılık, kış döneminde 13302 adet melez tohum alınmış, meyve başına tohum sayılarına bakıldığında; sırasıyla 28.2 ve 65.5 adet tohum/meyve oluştuğu belirlenmiştir (Çizelge 2). Buradaki melezleme başarısı üzerine kombinasyonlarında etkisi olmasına rağmen, mevsimin ve kontrollü şartların sağlanmasının açık etkisi ortaya çıkmıştır. Kış dönemi sera şartlarında patatesin çiçeklenmesi ve melez meyve oluşmasını teşvik için suni ışık 
kullanılarak uzun gün şartları oluşturulmuştur. Nitekim, gün uzunluğunun 16 saat olmasının patateste çiçeklenmeyi teşvik ettiği ve melezleme başarısını arttırdığı melezleme işlemi için en iyi tozlama zamanının sabahın erken ve serin saatlerinde çiçekler tamamen açıldıktan kısa bir süre sonra olduğu bildirilmiştir (Fehr and Hadley 1980; Poehlman and Sleper 1995). Kış döneminde kontrollü sera şartları oluşturularak melezleme işlemleri yapılırken, yaz döneminde farklı ortamlarda melezlemeler yapılarak, ortamların da etkilerine bakılmıştır. Elde edilen bulgular Çizelge 3'te özetlenmiştir. Buna göre deneme yer alan 15 kombinasyonda melezleme yapılan çiçek sayılarının açık arazi şartlarında (403) daha fazla olduğu, bunu yüksek rakımlı Artova şartlarındaki açık arazi (385) ve tül sera ortamının (351) takip ettiği, yaz döneminde cam sera (63) ve düşük rakımlı yer olan Kazova şartlarındaki tül sera ortamınlarında (58) daha az sayıda çiçekte melezleme yapılabildiği görülmüştür (Çizelge 2). Bu durum melez meyve oluşmasına farklı şekilde yansımış olup, Tokat-Kazova açık arazi şartlarında melez meyve oluşumu esas alınarak, hesaplanan melezleme başarısı \%2 iken, bu oranlar sırasıyla Tokat tül serada $\% 5$, Artova açık alanda \%6 ve Artova tül serada \%9'a çıkmıştır.

Melezleme çalışmalarında hedef melez tohum elde etmek olduğuna göre en fazla

Çizelge 2. 2014 Yılı yaz ve kış dönemlerinde yapılan melezleme, elde edilen melez meyve-tohum sayıları Table 2. Amount of hybrid fruits and seeds obtained from crosses made in 2014 summer and winter

\begin{tabular}{|c|c|c|c|c|c|c|c|c|c|c|}
\hline \multirow[t]{2}{*}{ Kombinasyonlar } & \multicolumn{2}{|c|}{$\begin{array}{l}\text { Melezlenen } \\
\text { Çiçek } \\
\text { Sayısı }\end{array}$} & \multicolumn{2}{|c|}{$\begin{array}{l}\text { Melez } \\
\text { Meyve } \\
\text { Sayısı }\end{array}$} & \multicolumn{2}{|c|}{$\begin{array}{l}\text { Meyve tutma } \\
\text { oranı (\%) }\end{array}$} & \multicolumn{2}{|c|}{$\begin{array}{l}\text { Melez Tohum } \\
\text { Sayısı }\end{array}$} & \multicolumn{2}{|c|}{$\begin{array}{c}\text { Meyve başına } \\
\text { tohum sayısı }\end{array}$} \\
\hline & Yaz & Kış & Yaz & $\mathrm{K}$ ış & Yaz & Kış & Yaz & Kış & Yaz & Kış \\
\hline A2/11 X T6/28 & 20 & 52 & - & 1 & - & 1.9 & - & 38 & - & 38 \\
\hline $\mathrm{A} 3 / 110 \times \mathrm{A} 2 / 11$ & 171 & 119 & 5 & 32 & 2.9 & 26.8 & 317 & 3328 & 63.4 & 104 \\
\hline $10 / 15 \times A 3 / 223$ & 114 & 82 & - & 0 & - & - & - & - & - & - \\
\hline $\mathrm{A} 7 / 12 \times \mathrm{A} 10 / 15$ & 304 & 106 & 2 & 0 & 0.6 & - & 10 & - & 5.0 & - \\
\hline A8/34 X A13/1 & 26 & 103 & 4 & 24 & 15.3 & 23.3 & 10 & 1215 & 2.5 & 50.6 \\
\hline $\mathrm{T} 4 / 4 \times \mathrm{T} 6 / 28$ & 38 & 36 & - & 0 & - & - & - & - & - & - \\
\hline A2/11 X Melody & 11 & 27 & - & 2 & & 7.4 & - & 54 & & 27 \\
\hline A7/12 X Van Gogh & 32 & 193 & 1 & 18 & 3.1 & 9.3 & 20 & 952 & 20.0 & 52.8 \\
\hline A3/223 X Megusta & 86 & 142 & - & 1 & - & 0.7 & - & 34 & - & 34 \\
\hline $\begin{array}{l}\text { Başçiftlik B. X } \\
\text { A13/1 }\end{array}$ & 187 & 71 & 32 & 40 & 17.1 & 56.3 & 938 & 3728 & 29.3 & 93.2 \\
\hline $\begin{array}{l}\text { Başçiftlik B.X } \\
\text { Megusta }\end{array}$ & 169 & 94 & 10 & 44 & 5.9 & 46.8 & - & 1746 & - & 39.7 \\
\hline $\begin{array}{l}\text { 12- Başçiftlik B.X } \\
\text { Van Gogh }\end{array}$ & 10 & 60 & 1 & 31 & 10 & 51.7 & 2 & 2015 & 2.0 & 65 \\
\hline $\begin{array}{l}\text { 13- Aleddiyan S.X } \\
\text { Megusta }\end{array}$ & 6 & 26 & - & 6 & - & 23.0 & - & 130 & - & 21.7 \\
\hline $\begin{array}{l}\text { 14-Aleddiyan S.X } \\
\text { A2/11 }\end{array}$ & 86 & 30 & 10 & 3 & 11.6 & 10 & 534 & 62 & 53.4 & 20.7 \\
\hline $\begin{array}{l}\text { 15-Aleddiyan S.X } \\
\text { T6/28 }\end{array}$ & - & 5 & - & 0 & - & - & - & - & - & - \\
\hline Toplam/Ort. & 1260 & 1602 & 65 & 203 & 5.2 & 12.7 & 1831 & 13302 & 28.17 & 65.52 \\
\hline
\end{tabular}

Çizelge 3. Farklı ortamlarda yapılan melezlemeler ve elde edilen melez meyve-tohum sayıları

Table 3. Crosses made in different environments and amount of hybrid fruits obtained

\begin{tabular}{llllll}
\hline \multicolumn{1}{c}{ Ortamlar } & $\begin{array}{l}\text { Melezlenen } \\
\text { çiçek sayısı }\end{array}$ & $\begin{array}{l}\text { Melez } \\
\text { meyve sayısı }\end{array}$ & $\begin{array}{l}\text { Meyve oluşma } \\
\text { oranı (\%) }\end{array}$ & $\begin{array}{l}\text { Melez tohum } \\
\text { sayısı }\end{array}$ & $\begin{array}{l}\text { Tohum } \\
\text { sayısı/meyve }\end{array}$ \\
\hline Tokat-Kazova arazi & 403 & 7 & 2 & 229 & 32.7 \\
Tokat tül sera & 58 & 3 & 5 & 130 & 43.3 \\
Tokat-Artova arazi & 385 & 24 & 6 & 785 & 32.7 \\
Artova tül sera & 351 & 31 & 9 & 687 & 22.2 \\
Tokat cam sera* & 63 & - & - & - & - \\
Toplam/ort. & 1260 & 65 & 5.2 & 1831 & 28.2 \\
\hline
\end{tabular}


melez tohum Artova (rakım 1200 m) şartlarında yapılan melezlemelerden (785 adet tohum), bunu yine Artova tül sera (687 adet), 640 m rakımlı Tokat açık alan (229 adet) ve Tokat'taki tül sera şartlarından (130 adet) alındığı belirlenmiştir. Bu sonuçlar farklı melezleme ortamlarının patateste melezleme başarısını açık bir şekilde etkilediğini ortaya koymuştur. Tokat Artova yüksek rakımlı (1200 m) ve gece gündüz sıcaklık farkı belirgin olduğundan çiçeklenme ve melez meyve bağlama oranı, daha düşük rakımlı Tokat Kazova (640 m) şartlarından daha iyi sonuçlar vermiştir.

Konuyla ilgili Almenkinders (1992), Gopal (1994) ve Gopal (2006) kısa günlerin çiçeklenmeyi azalttığını ya da çiçek tomurcuklarının dökülmelerine neden olduğunu, yüksek rakımlı (tercihen 1500 m ve üzeri) yerlerde çiçek yoğunluğunun arttığını ve meyve bağlamanın daha fazla olduğunu bildirmişlerdir. Tokat Artova yüksek rakımlı (1200 m) ve gece gündüz sıcaklık farkı belirgin olduğundan çiçeklenme ve melez meyve bağlama oranı, daha düşük rakımlı Tokat Kazova (640 m) şartlarından daha iyi sonuçlar vermiştir. Konuyla ilgili Almenkinders (1992), Gopal (1994) ve Gopal (2006) kısa günlerin çiçeklenmeyi azalttığı ya da çiçek tomurcuklarının dökülmelerine neden olduğu, yüksek rakımlı (tercihen 1500 m ve üzeri) yerlerde çiçek yoğunluğunun arttığı ve meyve bağlamanın daha fazla olduğunu bildirmişlerdir.

\section{Sonuç}

Yaz döneminde cam sera şartlarında meydana gelen tuta böceği saldırısından dolayı çiçeklenme sonrasında bitkiler elden çıkmış olduğundan bir başarı elde edilememiştir. Çalışmada 2014 yılının yaz dönemindeki özellikle yüksek sıcaklıklarından dolayı, melezleme başarısı oldukça düşük düzeyde kalmıştır. Bu çalışmadan elde edilen sonuçlara göre, patateste melezleme başarısında en önemli faktörlerden birisinin ebeveyn uyumu olduğu, yoğun çiçek oluşturma ve melez meyve bağlamada bitkide gibberellik asit sentezinin önemli olduğu, bunun için uzun gün ve serin şartların gerektiği, kış döneminde kontrollü şartlarda melezlemenin oldukça başarılı olduğu, yaz dönemindeki yüksek sıcaklıkların olumsuz etkisine karşılık, yüksek rakımlı serin yerlerde açık alan ya da tül sera şartlarında da başarılı melezlemelerin yapıldığı, sıcaklığın $15-19^{\circ} \mathrm{C}$ arasında olması ve gece gündüz sıcaklık farkının oluşmasının melezleme başarısını arttırdığı sonuçları ortaya çıkmıştır. Diğer taraftan başlangıçta güçlü ve sağlıklı bitkilerin yetiştirilmesi, melezleme işleminin günün serin, tercihen sabahın erken saatlerinde yapılması, emaskulasyonu takiben melezlemenin hemen yapılması, stigmanın zedelenmemesi için izolasyonun yapılmaması da diğer öneriler arasında yer almaktadır.

\section{Teşekkür}

Bu makale TÜBITAK-TOVAG tarafından desteklenen 1130928 nolu projeden üretilmiştir.Bu yüzden TÜBİTAK'a teşekkür ederiz.

\section{Kaynaklar}

Anonim 2013. Food and Agriculture Organization. Statistic Data

Anonim 2014. Türkiye İstatistik Kurumu. http://tuikapp.tuik.gov.tr/bitkiselapp/bitkisel.zul

Anonim 2015. Tohum Tescil Sertifikasyon Merkezi Müdürlüğü, Tescilli Çeşitler Listesi

Almekinders C.J.M., Struik P.C., 1996. Shoot development and flowering in potato (Solanum tuberosum L). Pot Res., 39 : 581607

Brown J., Caligari P.D.S., 1989. Cross prediction in a potato breeding programme by evaluation of parental material. Theor Appl Gen., 77: 246-252

Brown C.R., 2011. The Contribution of traditional potato breeding to scientific potato Improvment. Potato Research, 54: 287-300

Chailakhyan M.K.H., 1971. Hormonal control of flowering in plants differing in their photoperiodic response. Fiziol. Rast. (Moscow), 18: 348-357

Er C., Uranbey S., 2009. Nişasta ve Şeker Bitkileri Ders Kitabı. Ankara Üniversitesi Ziraat Fakültesi.Tarla Bitkileri Bölümü. 3. Baskı. Yayın No:1573. Ders Kitabı: 525, Ankara

Esendal E., 1990. Nişasta-Şeker Bitkileri ve Islahı, Cilt. 1. Patates. 19 Mayıs Ün. Ziraat Fak Yayınları

Fehr W.R., Hadley H.H., 1980. Hybridization of crop plants. American Society of Agronomy and Crop Science of America. p. 420, USA

Gopal J., 1994. Flowering behaviour, male sterility, and berry setting in tetraploid Solanum tuberosum germplasm. Euphytica. 72:133142 
Gopal J., 2006. Considerations for Successful Breeding. p. 77-108. (Editör: Khurana SMP) Handbook of potato production, improvement, and postharvest management. Food Products Press, New York

Harris P., 1992. The Potato crop. the scientific basis for Improvement. Chapman \& Hall, London

Kurt O., 2004. Bitki Islahı, Ders Kitabı. 19 Mayıs Ün. Zir. Fak. Yayınları 2. Baskı. No: 43. Samsun

Markarov A.M., 2002. Causes of flowering of longday potato species under short-day and coldnight conditions. Russian Journal of Plant Physiology, 49(4) : 465 - 469

Mendoza H.A., 1987. Advances in Population Breeding and Its Potential Impact on The Efficiency of Breeding Potatoes for Developing Countries, In Production of New Potato Varieties (Editör: Jellis GJ, Richardson DE.), Cambridge University Press, Cambridge, P. 235-245
Metzger J.D., 1990. Comparison of Biological Activities of Gibberellins and Gibberellin Precursors Native to Thlaspi arvense L. Plant Physiol., 94 : 151-156

Muthoni J., Shimelis H., Melis R., Kabira J., 2012. Reproductive biology and early generation's selection in conventional potato breeding, Australian J. of Crop Science, 6(3): 488-497

Poehlman J.M. and Sleper D., 1995. Breeding field crops. $4^{\text {th }}$ ed. lowa State University Press, p: 419

Sleper D.A. ve PoehIman J.M., 2006. Breeding Field Crops, $5^{\text {th }}$ ed. Blackwell Publishing Professional. 2121 State Avenue, Ames, lowa

Struik P.C. ve Wiersema S.G., 1999. Seed potato technology. Wageningen: Wageningen Pers, $383 \mathrm{pp}$ 